\title{
A QUESTÃO DO CONSUMO E A PIRATARIA
}

\section{The issue of consumption and piracy}

\section{La cuentión del consumo y la piratería}

Paulo Roberto Monteiro de Araujo ${ }^{1}$

\section{Resumo}

O texto tem a preocupação de analisar o problema da relação entre desejo, consumo e pirataria. Deste modo, o nosso objetivo é mostrar a formação do desejo como elemento central para compreendermos os motivos que levam as marcas a combaterem a pirataria. Palavras-chave: pirataria, consumo, desejo.

\begin{abstract}
The major concern of the text is to explain the interaction between desire, consume and piracy. Beside, our purpose is to show how the desire's formation in advance capitalism is the key to comprehend the combat against piracy.
\end{abstract}

Keywords: counterfeiting, consumption, desire.

\section{Resumen}

El texto tiene uma preocupación en analisar el problema de la reación entre deseo, consumo y peratería. De este modo, nuestor objectivo es mostrar la formación del deseo como elemento central para la comprehesion de los motivos que llevan las marcas a combater la piratería.

Plavras-clave: piratería, consumo, deseo.

A questão da autoria na Modernidade pode ser compreendida em uma dimensão estética a partir do Romantismo Alemão: reconhecimento da genialidade daquele que elabora uma determinada obra de Arte. Deste modo, a discussão sobre a autoria se vincula ao processo de reconhecimento da subjetividade, compreendida como

\footnotetext{
${ }^{1}$ Docente no Programa de Pós-graduação em Educação, Arte e História da Cultura da Universidade Presbiteriana Mackenzie.
} 
identidade singular que apreende aquilo que os outros não conseguem captar: seja na esfera cognitiva, seja na esfera sensível da percepção.

A ideia de genialidade artística revela na história da cultura ocidental um novo patamar no que se refere às práticas sociais. O Romantismo Alemão marca uma diferença com outros períodos históricos do ocidente. Na Idade Média não havia ainda o conceito de autonomia artística ou algo do gênero. $\mathrm{O}$ artista em sua elaboração não era conduzido por si mesmo, como sujeito, mas por Deus, o verdadeiro criador da obra. O artista era um instrumento do divino em seu processo de elaboração artístico. Podemos dizer que até o final da Renascença, o artista não era autônomo em seu próprio fazer artístico. Somente com o advento do movimento Romântico Alemão é que o conceito de sujeito ganha status de reconhecimento. Com o desenvolvimento de um vocabulário de valor referente aos significados de autonomia, de sujeito e de identidade, o artista passa a ser aquele que detém a determinação da obra, ou seja, ele tem o direito sobre a sua criação.

Como salienta Hegel, em sua Filosofia do Direito, as qualidades do espírito (compreendido como razão) quando se concretizam em uma exterioridade (sensível), como é o caso da invenção de algum instrumento, da criação uma escultura artística ou algo do gênero, ocorre uma espécie de assimilação, por parte dessas qualidades do espírito, do aspecto externo da coisa, isto é, da sua aparência (Schein). É como se acontecesse uma espécie de coisificação das qualidades internas do espírito, ou seja, da razão que se torna algo palpável à nossa dimensão sensível. Sendo assim, estando no estado da aparência da coisa, as qualidades do espírito tendem a ser negociadas por aqueles que as possuem, no caso, os artistas.

Deste modo, coloca-se em questão, por exemplo, se um artista tem juridicamente posse da obra de arte que ele produziu. Portanto, se ele tem realmente direito de dispor de algo que lhe é interno (como aptidão, conhecimento, disposição) como algo externo (como coisa - a obra), de forma que possa negociá-lo. Para Hegel fica claro que o artista como sujeito que produziu um quadro, ou outro produto qualquer que esteja na esfera da produção do espírito (razão), tem o direito de negociá-lo como se fosse uma coisa. Não há em termos ontológicos uma modificação real do conceito interno das qualidades do espírito.

Quando se trata da negociação dessas qualidades do espírito (razão) no plano externo, o que acontece é uma tomada de posse pela pessoa, como sujeito (o artista) 
daquilo que é interno a si mesmo, por meio da exteriorização das suas obras, que surgem como coisas potencialmente negociáveis. A negociação é somente o modo pelo qual se exterioriza o caráter da posse dessa capacidade criativa do espírito (razão). Só se pode fazer um contrato ou negócio a partir daquilo que se tem posse. Hegel no $§ 41$ da sua Filosofia do Direito salienta que a pessoa como sujeito tem o direito que exteriorizar a sua posse interna dos seus produtos ao transplantá-los para o mundo das coisas negociáveis. Está aí o caráter exterior das qualidades do espírito. Deste modo, o artista como sujeito de suas capacidades espirituais internas tem o direito de propriedade de suas obras como exteriorização de tais capacidades. Daí para a cultura ocidental a pirataria é um crime, pois significa roubar a propriedade alheia, isto é, roubar a capacidade daquele que possui a genialidade de elaborar uma obra de arte. Hegel faz parte desse movimento de construção de um vocabulário de valor que reconhece o direito do artista, como aquele que expressa as qualidades internas da razão, sob a forma de coisas externas na dimensão da arte.

A construção de um Vocabulário de Valor tem como objetivo formar um conjunto de significados referenciais que são internalizados entre aqueles que pertencem a uma mesma comunidade linguística. Tal comunidade pode ser compreendida também como sendo a mesma comunidade cultural, em que seus membros participam de semelhantes significados, vinculados a um determinado vocabulário de valor. A partir da elaboração de um vocabulário de valor podemos compreender a formação de novos desejos, no sentido de realização como Pessoa. Sendo assim, a construção de um vocabulário de valor significa que o artista é reconhecido em sua dimensão humana e, por isso mesmo deve ser preservado o direito de proprietário de sua obra como expressão de sua identidade humana.

No entanto, cabe lembrar que há uma diferença entre aquilo que o filósofo canadense Charles Taylor diz sobre a elaboração de um vocabulário de valor, em que o outro deve, por exemplo, ser reconhecido em suas obras, como artista, e a realização dos desejos na esfera das coisas, mesmo sendo essas obras de arte. A realização dos desejos nas coisas tem a ver com a utilidade e satisfação das pessoas, não das suas dignidades humanas (é disso que trata um vocabulário de valor). É neste aspecto que podemos nos voltar para compreender a relação entre o Consumo e a Pirataria.

O consumo como ocorre no já conhecido Sistema Capitalista está voltado para o ato de "devorar" as novidades por ele produzidas. Lembrando ainda Hegel em sua 
Filosofia do Direito, a partir da relação imediata com o mundo, a pessoa se limita ao desejo de tomar posse dos objetos que surgem ao seu redor, embora esse tomar posse seja o primeiro ato de construção do conceito de liberdade. No Capitalismo, esse tomar posse não significa propriamente o se ganhar como pessoa consciente da sua liberdade, mas dos seus desejos imediatos cujas premissas estão no desenvolvimento de um hiperconsumo já apontado por Lipovetsky em obras como O Império do efêmero (ver a segunda parte dessa obra A sedução das coisas. Companhia das Letras, p.184).

O Capitalismo para manter a sua dinâmica precisa permanecer em altos níveis de consumo. Deste modo, cada vez mais as pessoas precisam internalizar o referencial significativo do "ato de devorar novidades". O problema está na sofisticação cada vez maior dos objetos oferecidos para serem consumidos como Bolsas Gucci, Jeans Diesel, Perfumes Prada, etc. Neste sentido, surge o problema da autoria. Se na história do ocidente, como analisamos acima, tivemos a elaboração do conceito de sujeito cujas qualidades espirituais se tornaram reconhecidas por meio de um vocabulário de valor, hoje vemos que tal vocabulário não tem mais o mesmo significado em seu fundamento. O reconhecimento daquele como sujeito que elabora determinada obra não está mais na pauta das preocupações da cultura do consumo. A autoria é o que menos importa, no sentido de reconhecer o seu autor em sua dignidade humana. O que importa é o que tal autor significa para a manutenção da marca. Não é por acaso que, no mundo da moda, diversos estilistas considerados talentosos perderam as suas autorias, viraram marcas para conglomerados financeiros (os estilistas tornaram-se seus funcionários). Sendo assim a discussão em relação à pirataria não está mais no âmbito do respeito ao autor de alguma obra, seja ela artística ou não. O que importa é a capacidade que o trabalho do criador tem de manter a marca no mercado em um alto grau de consumo. Daí o motivo de se combater a pirataria não está simplesmente no respeito ao autor, mas na conservação do valor da mercadoria, não naquele sentido relativo ao trabalho que Marx concebeu em o Capital. Manter o valor no capitalismo avançado é manter o fetiche da própria mercadoria, principalmente quando se trata das mercadorias de luxo. É o caso do mercado de bolsas femininas; ter uma bolsa Louis Vuitton virou sinônimo de status, por mais que milhares de mulheres andem com tais bolsas pelos corredores dos shoppings Centers. Exibir uma bolsa Louis Vuitton significa expressar a sua capacidade de consumo, pois é tal capacidade que lhe confere uma "dignidade" social. 
A manutenção dessa suposta "dignidade" social dos compradores das marcas, faz com que haja o combate àquilo que se mostra como sendo o mesmo de algo que possui marca. O que eu quero dizer é que o produto pirata ao imitar o produto original, busca minar as bases da idealização valorativa do que é marca sem afetar a sua aparente determinação de ser original. Por mais que a imitação pirata seja vulgar, a aparência de coisa permanece em seu caráter perceptivo na esfera do consumo (em seu significado social amplo - as pessoas ainda reconhecem a marca no produto não original), cuja estrutura lógica é a realização de desejos em sua imediata sensibilidade. Cabe lembrar que o imediato sensível do desejo não tem em si mesmo o caráter critico para fazer supostas diferenciações do que é original ou não. Daí pouco importa para o sensível imediato dos desejos qual o material que a pirataria usa para fabricar as suas imitações.

A pirataria barateia a realização do desejo de um amplo grupo social que procura realizar desejos não por simples imitação do modo de vida dos compradores de marcas caras, mas sim de consumir algo fora do seu âmbito de consumo cotidiano. O problema da pirataria para as marcas, incluindo principalmente as de luxo, está em sua difusão para aqueles que não sustentam a sua idealização valorativa original. A pirataria ao democratizar o desejo de consumir marcas, contraditoriamente elimina tal desejo, pois acaba com o fetiche da marca, do seu suposto status social.

A pirataria é combatida, como salientamos anteriormente não por uma questão de reconhecimento dos seus autores, mas pela manutenção do desejo de consumir algo que aparentemente não está ao alcance de todos. Cidades como São Paulo que detém mais de $70 \%$ do mercado de luxo brasileiro, em que boa parte da sua população não pode consumir marcas que lhe dão status, criam referenciais significativas de desejos, mesmo para aqueles que não podem consumir objetos de luxo.

Contraditoriamente tais referenciais criados pelas marcas de luxo geram cada vez mais a concepção do fabricar aquilo que é do outro, para oferecer ao mercado como sendo aparentemente igual. A pirataria significa a tentativa de democratizar o consumo, ou mais do que o simples consumo, o consumo como status social. É claro que o consumo por status não é uma novidade na história recente do consumo, mas o que é novidade é o fato das pessoas terem como referencia a ideia de participar do espetáculo que as marcas se tornaram. Não quero fazer aqui nenhuma referencia a ideia de espetáculo do Guy Debord, mas sim a ideia de alguém se tornar sujeito por meio do outro que não é ninguém. Neste aspecto o pensamento de Heidegger é fundamental. 
Se tornar sujeito por meio dos objetos é o modo encontrado em nosso cotidiano de consumo para nos tirar da tarefa de nos tornarmos nós mesmos. Não havendo mais referenciais valorativos culturais, éticos e políticos, a vontade individual como subjetividade se encontra naufragada existencialmente. Daí a despreocupação ou a não ocupação conosco, com a nossa existência humana. É neste aspecto da não ocupação com a existência, que as marcas elaboram as suas linguagens, no sentido de dar alguma determinação significativa à indigência existencial da nossa contemporaneidade. Não se trata de uma simples acusação moralizante em relação às marcas e as suas linguagens voltadas para a manutenção do alto consumo, mas sim de compreender o que funda ou dá origem aos novos formatos de consumo e a preocupação em combater a imitação no que se refere aos produtos de luxo.

A contradição daqueles que querem ser sujeitos através dos objetos de consumo oferecidos pelas marcas é se tornarem piratas; pois pegam algo que não são originalmente deles para imitar algo que não é originalmente de ninguém. $\mathrm{O}$ status de se ter uma bolsa Louis Vuitton é uma forma metafórica de piratear o significado de sujeito, elaborado culturalmente pelo ocidente. Ser sujeito, então, é participar do que chamei do espetáculo das marcas. Tal espetáculo se determina por meio não mais da linguagem publicitária com a sua triunfante sofisticação imagética, mas sim da invenção de um modo de ser cuja determinação está no agraciar que os objetos trazem para corpo compreendido agora como o lugar que deve refletir o que nós somos, sujeitos. Daí a cueca Calvin Klein, os jeans da Diesel, os casacos da Burberry. Sendo assim Prada, Gucci, Dior, entre outras se tornam uma espécie de nome de família que o corpo consome como sujeito, sem ser. O corpo como lugar que reflete o consumo de marcas para se tornar sujeito traz em si o problema do desejo. Cabe lembrar aqui do livro de Harry G. Frankfurt intitulado The importance of what we care about, cuja preocupação se vincula à problemática do desejo. Frankfurt em um dos textos que compõe o referido livro Liberdade da vontade e concepção de pessoa (Freedom of the will and the concept of a person) analisa a questão relacionada aquilo que ele chama de um desejo de primeira ordem (instintivo - em seu sentido passivo) e de uma segunda ordem (vontade - em um sentido ativo).

Para Frankfurt, alguém que se limita aos desejos sem questioná-los, permanecendo em uma simples escolha de querer ou não realiza-los, estaria nisso que salientamos acima de primeira ordem. Alguém que permanece nesse estádio de desejo, 
Frankfurt diz que não poderia ser considerado como pessoa, pois mesmo havendo algum tipo de racionalidade em suas decisões, não há uma avaliação sobre o próprio desejo, isto é, uma avaliação sobre o que move o seu desejo. Já em um desejo de segunda ordem há uma preocupação com o que move um determinado tipo de desejo, por isso nesta segunda ordem aparece o conceito de vontade (volition). Deste modo, um desejo de segunda ordem pode se tornar uma vontade de segunda ordem, cujo cerne é a preocupação ou o cuidado com os conflitos que existem nos desejos. Eis o motivo de Frankfurt dizer que para uma pessoa ser considerada humana ela precisa ter o discernimento do seu próprio desejo como algo que se sabe como desejo naquilo pretende ser qualitativamente.

Apesar da tese forte de Frankfurt de chamar aqueles que permanecem em desejos que ignoram os seus conflitos desejantes de wantons (que em uma tradução imediata poderia ser dito em português como aqueles de desejos indeterminados ou sem conflitos), tal termo pode nos ajudar a compreender a estrutura do desejo na esfera do mercado de bens de luxo, por exemplo. Digo isto não para concordar com as teses de Frankfurt sobre o conceito de agente humano em contraponto a passividade dos wantons, mas para compreender que, o quê está em jogo nas marcas é a sua dimensão de realização de algo que em nossa temporalidade pós-moderna não comporta mais: a ideia de sujeito moderno concentrado em seu ato pensante sobre si e sobre o mundo. Este algo que chamei atenção refere-se à realização do corpo que quer ser não mais por meio da sua autoexibição, mas através de algo que lhe traga uma marca para ser mostrada no espaço público. Daí as bolsas Louis Vuitton serem tão usadas, sejam originais ou não, pois apesar dessas terem virado algo comum nos mais diferentes espaços, elas garantem uma marca ao corpo daquelas (os) que as usam. Os objetos com o grife das marcam dão ao corpo uma qualidade que não é mais intrínseco a ele mesmo. A contradição de nossa época que valoriza a forma física é fazer com que tal valor perca a sua importância quando se trata do uso das marcas. O objeto não é mais o complemento do corpo, mas a expressão dele, da sua capacidade de realizar o desejo que ele quer através de algo que lhe qualifica perante os outros. É a marca que qualifica o corpo, que lhe confere uma forma de reconhecimento do outro no espaço da convivência.

A estrutura do desejo que se realiza através das marcas se funda nessa dimensão de garantir ao corpo algo que lhe dê distinção no espaço público, sem ter que dá 
satisfação seja ao seu intelecto seja à sua existência humana. A preocupação aqui não é fazer nenhum juízo moral ou político sobre esse modo de ser do desejo em nossos dias, mas mostrar a necessidade de interpreta-lo como forma de compreender os motivos que fazem as marcas se preocuparem cada vez mais com a proteção de seus produtos frente à Pirataria. Tal preocupação se encontra na necessidade mesma de garantir esse algo, que salientamos acima, para o corpo como forma de realização de si através de outra coisa que não ele próprio. As marcas oferecem tal algo para os corpos e, por isso mesmo, não interessa a elas verem profanados seus produtos pela pirataria.

Deste modo, a pirataria é o elemento corrosivo desse modelo de desejo que se construiu em nossa era do hiperconsumo, principalmente, em sua versão de luxo. Quanto mais os produtos de marcas de luxo vão se sofisticando e ganhando status de coisas hiperespeciais para os corpos, maior a necessidade de se combater a pirataria. Temos assim a formação de um mapa da nossa vida cultural pós-moderna cujo cerne está no modo como o desejo se estruturou em nosso capitalismo atual. As marcas reconhecem a estrutura desse desejo e sabem da sua importância para a manutenção do consumo em níveis elevados. Daí os elos entre corpo, desejo, marca e o contraponto destes, a pirataria. Sendo a pirataria o elemento corrosivo das marcas ele pode ser o motor para alavancar uma discussão sobre a estrutura do próprio desejo que se formou em nossa era.

É claro que as práticas da pirataria é uma forma de geração de capital em que o respeito à autoria do outro não é considerado, no entanto o que tais práticas nos dizem, pelo menos no nível do pensamento conceitual, é que existe a busca pela diferenciação dos desejos daqueles que podem consumir objetos especiais frente aos outros que não o podem fazer. Mas não é só isso. O problema não está simplesmente no desejo de buscar a diferenciação de classe social, essa busca já é evidente em nossa história sóciopolítico-cultural, mas sim pela busca de algo que dê aos corpos uma qualidade que está fora deles mesmos. Assim o desejo de alguém que pode consumir marcas de luxo não está mais no corpo como elemento fundador das vontades, mas sim no objeto fabricado em condições especiais, isto é, não massificado.

O objeto passa ter valor intrínseco para a realização do desejo, pois é ele que dá o tom e o vetor tanto para mim (para minha estrutura interna, isto é, psíquica e existencial) como para a minha importância frente ao outro sem que se precise provar qualquer tipo de qualidade pessoal: cultura, formação educacional, caráter, 
sensibilidade, consciência política, etc. $\mathrm{O}$ objeto fundado na marca faz uma espécie de milagre para a nossa realização desejante de ser. A nossa identidade não precisa mais ser desenvolvida ao longo da nossa vida pessoal, do nosso esforço de compreendermos o que estamos elaborando para nós mesmos. Não precisamos mais fazer um interpretação daquilo que somos ou queremos ser. O objeto nos lança fora daquilo que falamos acima, a partir de Heidegger, sobre a necessidade existencial que temos de nos ocuparmos de nós mesmos.

Para finaliza, cabe dizer mais uma vez que na presente análise sobre a relação consumo e pirataria não elaboramos nenhum discurso contra o desejo estruturado nas marcas ou ainda reducionismos conceituais a respeito de tal desejo. A nossa pretensão foi fazer uma hermenêutica do desejo no horizonte do consumo das marcas e o conflito destas em relação à pirataria.

\section{REFERÊNCIAS BIBLIOGRÁFICAS}

ARAUJO, Paulo R. M. Charles Taylor: par uma ética do reconhecimento. São Paulo. Edições Loyola, 2004.

. A Fragmentação da Eticidade na Sociedade Civil Burguesa na Filosofia do Direito de Hegel. 1994. Dissertação (Mestrado em Filosofia) Universidade de São Paulo.

FRANKFURT, Harry G. The Importance of what we care about. Cambridge. Cambridge University Press, 1997.

HEGEL, G.W.F. Grundlinien der Philosophie des Rechts. Hamburg. Felix Meiner Verlag, 1995.

. Principes de La Philosophie de Droit (trad. Robert Derathé). Paris. Vrin, 1986.

HEIDEGGER, Martin. Ser e Tempo. Petrópolis. Ed. Vozes, 2005.

LIPOVETSKY, Gilles. O Império do efêmero - A moda e seu destino nas sociedades modernas. São Paulo. Companhia das Letras, 2010.

. Os Tempos Hipermodernos. São Paulo. Editora Barcarolla, 2004.

TAYLOR, Charles. As fontes do Self - A construção da identidade moderna (trad. Adail U. Sobral e Dinah de Azevedo de Abreu). São Paulo. Edições Loyola, 1997. 
A questão do consumo e a pirataria

de Paulo Roberto Monteiro de Araujo

Data de recebimento: 20/11/2011

Data de aprovação: 05/12/2011 